\title{
Derecho a la educación y evolución legislativa en el acceso de las personas con discapacidad al sistema educativo español: de la exclusión a la inclusión educativa.*
}

Law and education and legislative evolution in the access of people with disabilities to the Spanish educational system: from exclusion to educational inclusion Cristina Castell Cerezo ${ }^{1 \otimes}$, Rosa María Espada Chavarría ${ }^{2}$

Fecha correspondencia:

Recibido: 25 de abril de 2020. Revisión: 29 de abril de 2020. Aceptado: 7 de mayo de 2020.

Forma de citar:

Castell- Cerezo, C y Espada-

Chavarria, R. "Derecho a la educación y evolución legislativa en el acceso de las personas con discapacidad al sistema educativo español: de la exclusión a la inclusión educativa." En: Revista CES Derecho. Vol. 11, No. 2, junio a diciembre de 2020, 137-159.

Open access

Términos de uso

Licencia creative commons

Etica de publicaciones

Revisión por pares

Gestión por Open Journal System DOl: http://dx.doi.org/10.21615/ cesder.11.2.8 ISSN: 2145-7719

\section{Sobre el artículo:}

Artículo de revisión. Grupo de Investigación Diversia. Línea de investigación: Personas con discapacidad, Inclusión y Accesibilidad.

\section{Resumen}

Es necesario conocer y explorar las diferentes leyes y normativas que se han ido sucediendo en España y entender el reciente recorrido histórico en educación inclusiva y atención a la diversidad y que han determinado el acceso y la práctica educativa en el alumnado con necesidades específicas de apoyo educativo, especialmente en el alumnado con necesidades educativas especiales derivadas de su discapacidad. Discriminación y exclusión social y educativa en el trato, en el lenguaje, en los medios y en el acceso a la educación, como se muestra en los modelos derivados de la Constitución de 1812 y que perduran sin cambios hasta mitad del siglo XIX debido al desconocimiento, carencias y ambigüedades reflejadas en las normativas y que son especialmente analizadas en esta investigación para las etapas de educación Infantil y Primaria principalmente. Leyes que han sido aplicadas a lo largo del tiempo, más como intención que como realidad. Circunstancia que empieza a cambiar bajo un nuevo paradigma, como modelo educativo más equitativo, de derecho y con más garantías para el todo el alumnado.

Palabras clave: Derecho a la educación, Diversidad, Educación inclusiva, Necesidades educativas especiales, Legislación educativa.

\section{Abstract}

It is necessary to know and explore the different laws and regulations that have been taking place in Spain and to understand the recent historical journey in inclusive education and attention to diversity and, that have based and determined the educational practice in students with specific needs of educational support, especially in students with special educational needs derived from their disability. Discrimination and social and educational exclusion in the treatment, in the language, in the media and in the access to education, as shown in the models derived from the Constitution of 1812 and which remained unchanged until the middle of the 14th century, due to the lack of knowledge, deficiencies and ambiguities reflected in the regulations and which are especially analyzed in this research for the Infant and Primary education stages. Laws that have been applied 


\section{Sobre los autores:}

1. Escuela Internacional de

Doctorado de la Universidad

Rey Juan Carlos. (Docente

asociada y doctoranda en

la Escuela Internacional de

Doctorado de la Universidad

Rey Juan Carlos).

2. Facultad de Ciencias

Jurídicas y Sociales

de la Universidad Rey

Juan Carlos. (Docente

e investigadora en la

Universidad Rey Juan

Carlos. Doctora en

Educación. Especialidad en

Discapacidad e inclusión. over time, more as an intention than as a reality. Circumstances that are beginning to change under a new paradigm, as an educational model that is more equitable, based on rights and with more guarantees for all students.

Abstract: Law and Education, Diversity, Inclusive Education, Special Education Needs, Education Legislation

\section{Introducción}

Cabe, como introducción para el estudio sobre las normativas dentro del sistema educativo y social español, definir éste como un proceso cambiante, entendiendo que, en este cambio hacia una educación inclusiva en la sociedad, todos somos responsables ya que somos los actores principales de esos cambios (Mora y Aguilera, 2000)

El presente artículo, tiene como objetivo general el estudio de las leyes y normativas específicas publicadas en el Boletín Oficial del Estado (BOE) con el fin de concretar las iniciativas que se han llevado a cabo a través del tiempo y que han tenido mayor repercusión en el acceso al sistema educativo del alumnado con necesidades específicas de apoyo educativo y, concretamente, de aquellos que presentan una discapacidad. Este estudio de la evolución en la legislación y normativa nos permite comprender el alcance actual de la atención a la diversidad del alumnado y valorar como estos avances han contribuido al concepto de inclusión que hoy entendemos. Leyes emitidas por el Ministerio de Educación Nacional, Jefatura del Estado, Presidencia del Gobierno, Ministerio de Educación, Ministerio de Educación y Ciencia, Ministerio de la Presidencia, Ministerio de la vivienda, Ministerio de Educación, Cultura y Deporte y Ministerio de Sanidad y Seguridad Social.

\section{Etapa de la exclusión}

En España por la Real Orden de 27 de marzo de 1802 se concede una de las primeras asignaciones económicas de ayuda para la apertura del Real Colegio de sordomudos (Sánchez, 1994) con la aprobación de su Reglamento un año después (Gutiérrez, 1997), hechos que se sitúan como los primeros acontecimientos en la educación reciente y que contribuyen al rudimento del recorrido histórico español en atención a la diversidad.

La Constitución de 1812', en su título IX, de la Instrucción Pública, determina en su capítulo I unas especificaciones mínimas en materia de educación, exponiendo en su Dictamen de 1814 que "Sin educación, es en vano esperar la mejora de las costumbres; y sin estas son inútiles las mejores leyes..." (Delgado, 1994, pág. 80).

En 1855, por Real Decreto de 17 de junio, se establecen las bases para la Administración educativa (Carreras, A. y Tafunell, X., 2005) que servirán de referencia para la primera ley educativa o Ley Moyano, con amplitud de estructuración para los diferentes tipos de enseñanza, incluidas entre otras, referencias para los estudios universitarios además de la formación práctica que tendrán que recibir los docentes para su quehacer pedagógico (Escamilla, Lagares, García, 2006). Legislación reguladora de la Enseñanza de 9 de septiembre de 1857, derogada en la actualidad (Gómez, 2009) y que recoge en su artículo 6 una atención individualizada dirigida al alumnado con discapacidad visual y auditiva con el término de desgraciados.

1. Gaceta de España, número 55, de 02/05/1812, pág.462. Referencia: BOE-B-1812-683. Sitio web: https://www.boe.es/datos/pdfs/BOE//1812/055/ B00462-00462.pdf 
La primera enseñanza se dará, con las modificaciones convenientes, a los sordo-mudos y ciegos en los establecimientos especiales que hoy existen y en los demás que se crearán con este objeto: sin perjuicio de lo que se dispone en el artículo 108 de esta ley. (Ley Moyano², 1857. Título I. Artículo 6).

Ley que fija igualmente en su capítulo primero, artículo 108, la creación de centros que den respuesta específica a la atención de dicho alumnado.

Promoverá asimismo el Gobierno las enseñanzas para los sordo-mudos y ciegos, procurando que haya por lo menos una Escuela de esta clase en cada Distrito universitario, y que en las públicas de niños se atienda, en cuanto sea posible, a la educación de aquellos desgraciados. Título I, capítulo I, Artículo 108, Ley Moyano, 1857. (Gaceta de Madrid, número 258, de 14 de septiembre de 1924, págs. 1332-1333).

En la Gaceta de Madrid³, revista oficial de publicación periódica desde finales del siglo XVII, en su número 24, de lunes 24 de enero, de 1910, en el tomo I, pág. 173, se cita el Real Decreto se establece el Patronato Nacional de Sordomudos, Ciegos y "Anormales" y que adopta en el año 1914, las inaugurales acciones del Patronato Nacional de Anormales. Patronato que es posteriormente conocido como Instituto Nacional de Pedagogía Terapéutica (Ríos, 2005). Institución que, por el Real Decreto de 14 de septiembre de $1924^{4}$, muestra la diferenciación de estos tres colectivos pasando a organizarse como organismos independientes y que son denominados nuevamente como: Patronato Nacional de Sordomudos, Patronato Nacional de Ciegos y el Patronato Nacional de anormales.

(...) con el fin que procure que todos los sordomudos y ciegos en edad escolar reciban la enseñanza que, supliendo el defecto físico de que adolece, les haga aptos para poder adquirir un medio de vida que les libre de la pobreza, acaso de la mendicidad y al menos de la obligada dependencia de sus parientes y conciudadanos. (Gaceta de Madrid, número 258, de 14 de septiembre de 1924, págs. 1332-1333).

Diez años más tarde se crea el Patronato Nacional de Cultura de los deficientes, por el Decreto de 3 de abril de $1934^{5}$, con propuestas encaminadas más a acciones pedagógicas y asistenciales que educativas, formativas o culturales (Gaceta Madrid, número 96, págs. 123-124) con siete artículos, con el propósito de que "todos los centros e Instituciones oficiales destinados a la cultura de los deficientes físicos o mentales, ciegos, sordomudos, inválidos y anormales, sean afectos a un Patronato, que se denominará Patronato Nacional de Cultura de los deficientes" (Gaceta de Madrid, número 96, de 6 de abril de 1934, págs. 123-124). Primeros inicios también regulados por la Ley de 17 de julio de 1945, sobre Educación Primaria ${ }^{6}$, dentro de la denominada España autocrática, con grandes carencias de estructura y de control externo (Fernández \& Fernández, 2016, pág. 88). Epítome de 115 artículos, en el que no se advierte ninguna referencia al alumnado con discapacidad (Fernández \&

2. Gaceta de Madrid. Parte Oficial de la Presidencia del Consejo de Ministros. Ministerio de Fomento. Sitio Web: https://www.boe.es/datos/pdfs/ BOE/1857/1710/A00001-00003.pdf

3. BOE-A- 1910-659. Gaceta de Madrid, número 24. Sitio web: https://www.boe.es/datos/pdfs/BOE//1910/024/A00173-00173.pdf

4, BOE, número 258, de 14/09/1924. Referencia: BOE-A-1924-8704. Sitio web: https://www.boe.es/datos/pdfs/BOE//1924/258/A01332-01334.pdf

5. BOE, número 96, de 6 de abril de 1934. Referencia BOE-A-1934-3061) Sitio web: https://www.boe.es/datos/pdfs/B0E//1934/096/A00123-00124.pdf

6. BOE, número 199, de 18 de julio de 1945. Sitio web: https://www.boe.es/datos/pdfs/BOE/1945/199/A00385-00416.pdf 
Fernández, 2016) salvo unas concreciones mínimas dentro del epígrafe de "Escuelas de anormales, sordomudos y ciegos":

El estado, para atender a la niñez desvalida y proporcionarle educación adecuada, establecerá Escuelas especiales para niños anormales y deficientes mentales y fomentará las de iniciativa privada. Así mismo creará y fomentará Escuelas, igualmente especiales, para niños sordomudos, ciegos y deficientes físicos. Todas se regirán por reglamentos peculiares". (Artículo treinta y tres del Boletín Oficial del Estado, número 199 de 18 de julio de 1945, pág. 394).

Hay que especificar que durante esta década el sector privado asume el desarrollo de la mayoría de las iniciativas del país (Bisquerra, 1996, pág. 78) y que la labor del Patronato de educación de la infancia anormal, emerge en 1953. Este centro es dirigido a la asistencia de la anormalidad y a su diagnóstico temprano, punto de partida sobre una atención temprana; actual concepto que el Ministerio ${ }^{7}$ de Educación define como "logro que incidirá positivamente en la mejora del rendimiento escolar futuro" (Delgado, 2013, pág. 26) y como aspecto determinante en el desarrollo integral del alumnado. Dos años más tarde la institución es llamada Patronato Nacional de Educación Especial (PNEE), estableciéndose el marco de gestión, organización y perfeccionamiento necesario para su actividad (Bisquerra, 1996, pág. 78).

Quince años más tarde se aprueba el Decreto $1758 / 1960,{ }^{8}$ de 7 de septiembre, por el que se modifica el título de la actual Escuela Nacional de Anormales, en el Instituto Nacional de Pedagogía Terapéutica, dentro de unas tendencias sociales que demandan y donde imperan constantes transformaciones asistenciales. Se aconseja modificar la denominación en la descripción de la Escuela Nacional de Anormales por otro término que refleje de forma más amplia su función, evitando además contribuir a una terminología inadecuada que hiera la susceptibilidad de los alumnos y alumnas incluidos en la institución y sus familias (BOE, número 223, pág. 13047) argumentando con ello la necesidad de utilizar un lenguaje menos discriminatorio y advirtiendo la forma y el lenguaje como parte fundamental del desarrollo (Ortiz y Carrión, 2020, pág. 569).

El 24 de julio de $1962^{\circ}$ se dicta la Orden por la que se establecen las normas para solicitar la expedición del título de profesores especializados en pedagogía terapéutica, locución incorporada por Strauss a España en el año 1936 (Sánchez, 1994) dentro de un incesante apremio de la figura de este personal especializado (BOE, número 200, pág. 11887). Reconocimiento profesional e ineludible de condición pedagógica con la intención de la regularización de este colectivo pedagógico experto y denominado en otros países como especialistas en pedagogía curativa (Sánchez, 1997; Ríos, 2005), pedagogía de apoyo, ortopedagogía, defectología (Fernández, 2015, pág. 5), pedagogía especial o pedagogía correctiva entre otros (Sánchez, 1994, págs. 17-18).

Se prosigue con el derogado Decreto 2925/ 196510, de 23 de septiembre por el que se regulan las actividades del Ministerio de Educación Nacional en orden a la Educación Especial, el cual hace referencia al alumnado con discapacidad como

7. https://www.mecd.gob.es/educacion-mecd/areas-educacion/estudiantes/educacion-infantil.html.

8. BOE, número 223, de 16 de septiembre de 1960. Referencia: BOE-A-1960-13319. Sitio web: https://www.boe.es/diario boe/txt.php?id=BOE-A-1960-13319 9. BOE, número 200, de 21 de agosto de 1962. Referencia: BOE-A-1962-17284. Sitio web: https://www.boe.es/diario boe/txt.php?id=BOE-A-1962-17284 10. BOE, número 248, de 16 de octubre de 1965. Referencia: BOE-A-1965-18500. Sitio web: https://www.boe.es/boe/dias/1965/10/16/pdfs/A1406414065.pdf 
"subnormales físicos, psíquicos y escolares- Cl, sub" (pág. 14065) y en la que se expone la necesidad de un impulso para la asistencia de alumnos de las primeras etapas educativas y "jóvenes subnormales" (pág. 14065). Apelativo discriminatorio que se matiza con la derogada Ley 14/1970, de 4 de agosto, Ley General de Educación y Financiamiento de la Reforma Educativa (LGE) también conocida con el nombre del entonces ministro de educación Villar Palasí (Fernández \& Fernández, 2016, pág. 89). En esta ley se contempla una nueva etiqueta legal en su capítulo VII calificando a este alumnado como "deficientes e inadaptados" con la intención de promover el crecimiento personal según sus características propias (López, 1993).

La educación especial tendrá como finalidad preparar mediante el tratamiento educativo adecuado, a todos los deficientes e inadaptados para una incorporación a la vida social, tan plena como sea posible en cada caso, según sus condiciones y resultado del sistema educativo; y a un sistema de trabajo en todos los casos posible, que les permita servirse a sí mismos y sentirse útiles a la sociedad. (Artículo 49, Ley General de Educación11 de 1970, pág.12532).

Texto que genera según Irima (2005) una preocupación e inquietud hacia el proceso de normalización de importante "calado educativo" (Botella, 2018) que regla en su artículo 50 los criterios para la detección, diagnóstico y atención del alumnado, dentro de un paquete de medidas novedosas como la organización de la educación especial, denominada y contemplada en su artículo 51 con propuestas de un currículo, régimen y contexto independiente y separado de la educación general para los alumnos con deficiencias severas e integrados en los centros ordinarios en una modalidad paralela, es decir, con la segregación en aulas específicas de educación especial para el alumnado con deficiencias leves.

La educación de los deficientes e inadaptados, cuando la profundidad de las anomalías que padezcan lo haga absolutamente necesario se llevará a cabo en centros especiales, fomentándose el establecimiento de unidades de educación especial en Centros docentes de régimen ordinario para los deficientes leves cuando sea posible. (Artículo 51 Ley General, 1970, pág. 12532 - BOE 187).

En paralelo a otras disposiciones se sigue trabajando en la formación y asistencia de aquellos profesionales en educación especial. La Orden Ministerial ${ }^{12}$ de 9 de diciembre de 1972, sobre confirmación de nombramiento de maestros en escuelas de educación especial (pág.499) establece líneas cada vez más equilibradas en cuanto a recursos personales dentro de un texto centrado principalmente en la respuesta educativa. Tres años más tarde, el Decreto 1151/1975, de 23 de mayo, promulga la creación del Instituto Nacional de Educación Especial'13 (INEE) con la finalidad de contribuir a la preparación y apoyo para todas “(...) aquellas personas que sufran deficiencias o inadaptaciones..." (BOE, número 132, págs. 11325). Intención contemplada también, en el hoy derogado Real Decreto 1023/1976 $6^{14}$, de 9 de abril, por el que se crea el Real Patronato de Educación Especial (Rodríguez, et al. 2003, pág.308) y que especifica en solo seis artículos la bifurcación de vertientes de su ámbito de actuación, es decir, medidas dirigidas a la formación, a la amplitud social derivada

11. BOE del E. Número 187, de 6 de agosto de 1970. Sitio Web: https://www.boe.es/boe/dias/1970/08/06/pdfs/A12525-12546.pdf

12. BOE, Gaceta de Madrid, número 9, de miércoles 10 de enero de 1973.

13. BOE, número 132, de 3 de junio de 1975. Referencia: BOE-A-1975-11325. Sitio web: https://www.boe.es/buscar/doc.php?id=BOE-A-1975-11325

14. BOE, número 112, de 10 de mayo de 1976. Referencia: BOE-A-1976-9418. 
de ella y al tratamiento específico como respuesta a las denominadas deficiencias e inadaptación del alumnado a las que se dirige (BOE, número 112, pág. 9017).

Ese mismo año se firma el Real Decreto $2276 / 1976^{15}$, de 21 de septiembre, por el que se regula el Real Patronato de Educación y Atención a deficientes, en cuyo artículo primero, dispone el cambio de denominación del Real Patronato de Educación Especial contemplado en el Real Decreto 1023/1976, al de Real Patronato de educación y atención a deficientes con la "función de impulsar" dicha modalidad formativa para el alumnado con deficiencias, matizando en siete artículos una nueva propuesta para la integración social de los alumnos denominados como deficientes" (BOE, número 229, de 25 de septiembre de 1976, pág. 22334). Siendo posteriormente registrado como Real Patronato de Prevención a personas con minusvalía en el RD1475/1986 (Escobar, 2010) y modificado a través del Real Decreto, 405/1984 ${ }^{16}$, de 22 de febrero.

Ya en 1978, la Constitución Española17, norma suprema de ordenamiento jurídico español recoge a los largo de los diez puntos del artículo 27, la normativa sobre el derecho a la educación para todos, así como la garantía de tal cumplimiento por los poderes públicos (artículo 27, punto 3, pág.8) especificando que "la educación tendrá por objeto el pleno desarrollo de la personalidad humana en el respeto a los principios democráticos de convivencia y a los derechos y libertades fundamentales" (artículo 17, punto 2, pág.8). Otro artículo que es necesario mencionar en la Constitución Española es el artículo 49, donde los poderes públicos deberán llevar a cabo políticas para la "previsión, tratamiento, rehabilitación e integración de los disminuidos físicos, sensoriales y psíquicos a los que prestarán la atención especializada que requieran ..." (artículo 49, pág.11) con carácter protector, médico y rehabilitador, y como garantía de tal derecho fundamental. También, y en el mismo año, por el Real Decreto 2176/1978 se encomienda al Ministerio de Sanidad y Seguridad Social la realización y gestión del Plan de Prevención de la Subnormalidad ${ }^{18}$ (artículo 49) dentro de una transformación educativa descentralizada (INEE, 2006, pág.38).

Se avanza lentamente en el proceso integrador de las Instituciones públicas y acciones ratificadas en el Real Decreto 2276/1978, de 21 de septiembre y en el Real Decreto 2828/1978, de 1 de diciembre, por los que se regula el Real Patronato de Educación y Atención a Deficientes ${ }^{19}$ apareciendo nuevas modificaciones como la Orden Ministerial de 25 de junio de $1980^{20}$, por la que se desarrolla la organización y funciones del Real Patronato de educación y atención de deficientes, mostrando falta de iniciativas y situación de desamparo hacia este alumnado, vislumbrando un cambio entre los conceptos aptitudinales y actitudinales como valor educativo, ya que las "normas no son suficientes para poder cambiar el modelo educativo" (Canales y Romero, 2018, pág. 14) fuertemente establecido en este periodo educativo.

El Real Decreto 1475/1986, ${ }^{21}$ de 11 de julio, reestructura el Real Patronato de prevención y de atención a personas con minusvalía. Se señala por su repercusión histórica

\footnotetext{
15. BOE, número 229, de 25 de septiembre de 1978. Referencia: 24415. Sitio web: https://www.boe.es/diario boe/txt.php?id=BOE-A-1978-24415

16. BOE, número 52, de 1 de marzo de 1984. Referencia: BOE-A-1984-5078. Sitio web: https://www.boe.es/diario boe/txt.php?id=BOE-A-1984-5078 17. BOE, número 311, de 29/12/1978. Referencia: BOE-A-1978-31229. Sitio web: https://www.boe.es/buscar/act.php?id=BOE-A-1978-31229 18. BOE, número 222, de 16 de septiembre de 1978. Referencia: BOE-A-1978-23787. Sitio web: https://www.boe.es/diario boe/txt.php?id=BOE-A-1978-23787

19. BOE. Boletín Oficial del Estado, 7 de diciembre de 1978, núm. 292, pp. 27684 a 27685.

20. BOE, número 154, de 27 de junio de 1980. Referencia: Boe-A-1980-13668. Sitio web: https://www.boe.es/diario boe/txt.php?id=BOE-A-1980-13668 21. BOE, número 171, de 18 de julio de 1986. Referencia: BOE-A-1986-19223. Sitio web: https://www.boe.es/buscar/doc.php?id=BOE-A-1986-19223
} 
en el sistema educativo español y que es ampliado por el Real Decreto ${ }^{22} 2828 / 1978$, de 1 de diciembre, normativa reguladora del Real Patronato de educación y atención a deficientes, destacando de entre sus ocho artículos el dirigido a facilitar la promoción integral del alumnado, subrayando su artículo cuarto, punto cuarto y quinto, la rehabilitación de los deficientes y su integración social, evitando las barreras que puedan interferir en la integración de éste en los diferentes ámbitos (BOE, número 292, pág. 27684). Es necesario nombrar también las nuevas concreciones de lo que en la actualidad se define como accesibilidad y diseño para todos, concepto que comienza a tenerse en cuenta en el contexto educativo, aunque aún muy distante del concepto actual que se establece en la Ley Orgánica 5/1980, de 19 de junio, por la que se regula el Estatuto de los Centros Escolares (LOECE), reglamento que pormenoriza dentro de sus 39 artículos, "h) A la utilización de las instalaciones, mobiliario y material del centro, que habrán de adaptarse a sus necesidades físicas y psíquicas con las máximas garantías de seguridad e higiene" (BOE, número 154, de 27 de junio de 1980, pág. 14636). Un año más tarde, el Instituto Nacional de Educación Especial apuesta por una diferenciación en las aulas; denominadas abiertas o cerradas dependiendo de las dificultades, las gravedades y el carácter temporal de las mismas (Timón \& Hormigo, 2010, pág.30)

\section{Periodo de Integración}

Con la Ley 13/1982, de 7 de abril, de Integración Social de los Minusválidos (LISMI) ${ }^{23}$ se produce un notorio avance para las personas con discapacidad (Martínez, J.L., 2005). Según Navaridas (2013) el periodo de integración se sitúa en la década de los 90. Impulso integrador a través de las cuatro conspicuas líneas de actuación de esta ley: sanitaria, pedagógica, política y educativa. La LISMI detalla entre otros puntos los niveles, objetivos, integración y necesidad de equipos multidisciplinares o multiprofesionales (García, 2011) para la atención de "toda aquella persona cuyas posibilidades de integración educativa, laboral o social se hallen disminuidas, como consecuencia de una deficiencia, previsiblemente permanente, de carácter congénito o no, en sus capacidades físicas, psíquicas o sensoriales" (BOE. Artículo 7, Título II, Titulares de los derechos, página 6) así como otros puntos a considerar en sus artículos 23, 24, 25, 26, 27 y 28 , y dentro de la sección segunda, el tratamiento y orientación psicopedagógica y la Orden Ministerial de 9 de septiembre de $1982^{24}$, por la que se regula la composición y funciones de los equipos multiprofesionales dependientes del Instituto Nacional de educación especial, así como los principios e individualización e integración educativa (artículo $1^{\circ}$, página 24894) de los especialistas en colaboración con el profesorado de los centros educativos; la detección temprana de las "deficiencias, anomalías y trastornos" (artículo $3^{\circ}$ punto b, página 24894) de ese alumnado, con una respuesta adaptada a la problemática específica de cada alumno (artículo $3^{\circ}$, punto d, página 24894) como orientaciones concisas para ser desarrolladas por los profesionales y especialistas adjuntos a este Instituto. También se exponen los principios de sectorización y normalización, recogidos con anterioridad en el informe Warnock de 1978 (Ríos, 2005). El Decreto 334/1985, prevé para el alumnado "discapacitado" tres premisas claras "(...) en cuanto al ritmo, oportunidades y opciones..." (Sánchez, 1997, pág. 16).

\footnotetext{
22. BOE, número 292, de 7 de diciembre de 1978. Referencia: BOE-A-1978-29788. Sitio web: https://www.boe.es/diario boe/txt.php?id=B0E-A-1978-29788 23. BOE. Número 103, de 30 de abril de 1982. Referencia: BOE-A-1982-9983. Sitio Web: https://www.boe.es/buscar/pdf/1982/BOE-A-1982-9983-consolidado.pdf 
Aunque se trata de un texto indeterminado, el Real Decreto 2639/1982, de 15 de octubre, de ordenación de la Educación Especial ${ }^{25}$, con diecinueve capítulos, destaca el principio de "normalización", especificando en el mismo artículo punto 3, que las NEE serán cubiertas en su "...máximo grado posible a criterios y programas ordinarios" (BOE, número 253, página 29118). Definición que sobresale en el Decreto por la propuesta inclusiva que sitúa al alumnado con NEE, más cercano a su pleno derecho, con la disminución de limitación y permanencia en aulas de apoyo educativo con el objetivo de minimizar al máximo la permanencia en éstas, abogando por una inclusión y apoyo de este alumnado en las aulas ordinarias (Arnaiz, 2005, pág.21).

Cabe destacar también, la Orden Ministerial de 14 de junio de $1983^{26}$, por la que se desarrolla el RD 2639/1982, de 15 de octubre, de ordenación de la educación especial en lo que se refiere a los niveles de Preescolar y Educación básica, "...la atención educativa al disminuido se iniciará tan pronto como sea posible en el marco del sistema ordinario de educación preescolar, mediante la modalidad de integración completa." (Disposición novena, punto 1. BOE número 145, pág. 17158) y que hace énfasis en la etapa de preescolar al ser entendida como periodo fundamental en la formación del alumnado con necesidades educativas (Puigdellivol, 2007). Se ha de señalar también y, con solo dos artículos el Real Decreto 405/1984, de 22 de febrero, por el que se reestructura la composición de los Órganos del Real Patronato de Educación y Atención a Deficientes y donde se puntualiza sobre la coordinación y estructura necesaria para la promoción de los alumnos deficientes (BOE, número 52, pág. 5657).

Otro Decreto que concreta la prestación de servicios y con mayor evolución hacia la integración del alumnado es el Real Decreto 334/1985, de 6 de marzo, de Ordenamiento de la Educación Especial ${ }^{27}$, con diferencias entre las distintas modalidades de escolarización llevadas hasta la fecha, donde se pone de manifiesto el reconocimiento de la educación especial dentro de un sistema educativo ordinario, además de precisar y requerir la coordinación entre los centros y el fomento de programas individuales al margen del currículo ordinario para el alumnado con "minusvalía" (Grañeras, et al., pág. 22). Conceptos que van generando cambios y hechos consolidados como el principio de individualización que empieza a consolidarse en el proceso educativo, así como la integración, la sectorización y la normalización de los servicios, con una idea clara de educación para el desarrollo de la "vida" siguiendo acciones de integración educativa y como aprendizaje previo y necesario para la integración social. Ese mismo año, la Orden Ministerial de 20 de marzo de 1985, sobre la planificación de la educación especial y experimentación de la integración en el curso 1985-1986 aporta la obligatoriedad y la asistencia prioritaria para los "(...) alumnos afectados por disminuciones psíquicas, físicas o sensoriales..." para una escolarización en centros ordinarios y en régimen de integración (pág. 7755), modelo que sirve de modelo para posteriores publicaciones que se ciñen a éste y que son según Navaridas (2013) ejemplo del carácter integrador del momento.

De nuevo se redacta una nueva Ley Orgánica, la LODE 8/1985, de 3 de julio, donde se regula el Derecho a la Educación y cobertura a las demandas educativas

25. BOE, número 253, de 22 de octubre de 1982. Referencia: BOE-A. 1982-27328. Sitio web: https://www.boe.es/buscar/doc.php?id=BOE-A-1982-27328 26. BOE, número 145, de 18 de junio de 1983. Referencia: BOE-A-1983-17045. Sitio web: https://www.boe.es/buscar/doc.php?id=BOE-A-1983-17045 
con programas adecuados para ello, principalmente con iniciativas dirigidas al desarrollo educativo y bienestar social (BOE ${ }^{28}$, número 159, de 4 de julio de 1985 , pág. 21015) que fija las bases para las posteriores normativas y en cumplimiento del Decreto 334/198529 de 6 de marzo, de Ordenación de la Educación Especial, con medidas de integración para el alumnado con NEE al sistema ordinario, así como la proporción de alumnos de educación especial/docente especializado de dichos centros. Esta normativa es rectificada posteriormente por las Órdenes de 30 de enero de $1986^{30}$ que establece la proporción de alumnos de educación especial/docente especializado de dichos centros "(...) la orden establece las indicadas proporciones con la flexibilidad a que obliga la complejidad de la mencionada modalidad educativa, complejidad derivada, por un lado, de la diversidad de características, gravedad y heterogeneidad del alumnado disminuido o inadaptado..." (BOE, número 30, de 4 de febrero, pág. 4685) y por la Orden de 14 de mayo de $1986^{31}$ que establece de nuevo, una nueva correspondencia entre el personal de apoyo/alumnos en la educación especial.

Ese mismo año, se publica el Real Decreto ${ }^{32}$ 1475/ 1986, de 11 de julio, por el que se reestructura el Real Patronato de Prevención y de Atención a Personas con minusvalía y el actualmente derogado Real Decreto ${ }^{33}$ 969/1986, de 11 de abril, por el que se crea el Centro Nacional de Recursos para la Educación Especial (CNREE) siguiendo una corriente educativa de dotación de recursos para cumplir las demandas que cada vez se concretan más para una educación igualitaria "(...) las orientaciones básicas emanadas del Ministerio de Educación y Ciencia en relación con la educación especial, capaz de impulsar, analizar y coordinar las aceleradas transformaciones que se están produciendo en nuestro país en este campo" (BOE, 121, pág. 18092). Se fomenta también, los institutos nacionales antes mencionados y que son destinados a la reeducación de la comunidad sorda y de pedagogía terapéutica como centros específicos de educación especial de régimen ordinario por el Real Decreto $967 / 1986^{34}$, de 11 de abril.

Dos años más tarde, se firman tres nuevas normativas, la Orden de 25 de febrero de $1988^{35}$, sobre planificación de la educación especial y ampliación del programa de integración para el curso 1988/1989, incidiendo en la necesidad de la integración del alumnado con NEE dentro de instituciones ordinarias. Integración social que prioriza de entre las diversas opciones disponibles, aquella que reporta más posibilidades para el alumnado (Domenech, 2018).

Cabe señalar también la Orden Ministerial de 9 de junio ${ }^{36}$ de 1989, por la que se aprueba las instrucciones de organización y funcionamiento de centros escolares, señalando en su anexo I, las instrucciones necesarias para la "educación especial", insistiendo en la relevancia de la programación y de la atención individualizada

\footnotetext{
28. BOE, número 159, de 4 de julio de 1985. Referencia: BOE-A-1985-12978. Sitio web: https://www.boe.es/diario boe/txt.php?id=BOE-A-1985-12978 29. BOE, número 65, de 16/03/1985. Referencia: BOE-A-1985-4305. Sitio web: https://www.boe.es/buscar/act.php?id=BOE-A-1985-4305 30. BOE, número 30, de 4 de febrero de 1986. Referencia: BOE-A-1986-2899. Sitio web: https://www.boe.es/diario boe/txt.php?id=BOE-A-1986-2899 31. BOE, número 128, de 29 de mayo de 1986. Referencia: BOE-A-1986-13391. Sitio web: https://www.boe.es/diario boe/txt.php?id=BOE-A-1986-13391 32. BOE, número 171, de 18 de julio de 1986. Referencia: BOE-A- 1986-19223. Sitio web: https://www.boe.es/buscar/doc.php?id=BOE-A-1986-19223 33. BOE, número 121, de 21 de mayo de 1986. Referencia: BOE-A-1986-12316. Sitio web: https://www.boe.es/buscar/doc.php?id=BOE-A-1986-12316 34. BOE, número 120, de 20 de mayo de 1986. Referencia: BOE-A-1986-12283. Sitio web: https://www.boe.es/diario boe/txt.php?id=BOE-A-1986-12283 35. BOE, número 54, de 3 de marzo de 1988. Referencia: BOE-A-1988-5336. Sitio web: https://www.boe.es/buscar/doc.php?id=BOE-A-1988-5336 36. BOE, número 140, de 13 de junio de 1989. Referencia: BOE-A-1989-13351. Sitio web: https://www.boe.es/buscar/doc.php?id=BOE-A-1989-13351
} 
y comunitaria hacia este alumnado. Esta idea se mostrará posteriormente como uno de los pilares básicos de la inclusión (BOE, número 140, pág.18005).

De nuevo un Real Decreto, el 556/8937, en cumplimiento con los requisitos mínimos sobre accesibilidad en instituciones públicas, y de acuerdo con la Ley 13/1982, de integración social de las personas con minusvalía, asume como medida principal:

“(...) ampliar el concepto dimensional de las exigencias de accesibilidad, adaptándolo, con criterios más amplios, a las necesidades de espacio que requieren para desplazarse las personas con movilidad reducida y especialmente aquellos que utilizan silla de ruedas". (BOE, número 122, martes 23 de mayo de 1989, pág. 15353).

De nuevo aparece otra normativa, la $\operatorname{Orden}^{38}$ de 15 de enero de 1990, sobre la planificación de la Educación especial y ampliación del Programa de integración para el curso 1991-1992, con la intencionalidad de nuevo de promover la integración del alumnado en centros ordinarios, consiguiendo con ello mejores tasas de éxito. Integración en aulas ordinarias que vuelven a establecer las proporciones de profesional/alumnos en la atención educativa de los alumnos con necesidades educativas especiales a través de la Orden ${ }^{39}$ de 18 de septiembre de 1990.

La Ley Orgánica 1/1990, de 3 de octubre, de Ordenación General del Sistema Educativo $^{40}$ (LOGSE) decreta nuevas medidas equitativas e inclusivas dentro del capítulo $\mathrm{V}$, de la educación especial:

36.1"El sistema educativo dispondrá de los recursos necesarios para que los alumnos con necesidades educativas especiales, temporales o permanentes, puedan alcanzar dentro del mismo sistema de objetivos establecidos con carácter general para todos los alumnos."

36.2 "La identificación y valoración de las necesidades educativas especiales se realizará por equipos integrados por profesionales de distintas cualificaciones, que establecerán en cada caso planes de actuación en relación con las necesidades educativas específicas de los alumnos". 36.3 "La atención al alumnado con necesidades educativas especiales se regirá por los principios de normalización y de integración escolar". (BOE, número 238, página 28930).

Precisando en su punto 36.4 la evaluación del alumnado con necesidades educativas especiales. Artículos 37.1, 37.2, 37.3 y 37.4. Ley con iniciativas educativas más individualizadas y con nuevos principios, como se muestra en el artículo punto 3 , sobre la normalización y la integración, entendida como adaptación de una determinada atención que ha de ajustarse (Stainback \& Stainback, 2007) o como itinerario incierto y que debe ser revisado hacia una nueva perspectiva, pero de momento con un carácter compensatorio (Palomares, 2004, pág. 196). Contando entre sus puntos más importantes, aquellos dirigidos a las etapas de educación infantil y primaria a través de un currículo flexible, la reducción de las ratios y el empleo de adaptaciones individualizadas, tanto significativas como no significativas. Otras medidas son

37. BOE, número 122, de 23 de mayo de 1989. Referencia: BOE-A_1989-11632. Sitio web: https://www.boe.es/buscar/doc.php?id=BOE-A-1989-11632 38. BOE, número 41, de 16 de febrero de 1990. Referencia: BOE-A-1990-33985. Sitio web: https://www.boe.es/buscar/doc.php?id=BOE-A-1990-3985 39. BOE, número 236, de 2 de octubre de 1990, Referencia: BOE-A-1990-24063. Sitio web: https://www.boe.es/buscar/doc.php?id=BOE-A-1990-24063 40. BOE, número 238, de 4 de octubre de 1990. Sitio web: https://www.boe.es/boe/dias/1990/10/04/pdfs/A28927-28942.pdf 
también, la ampliación de la edad obligatoria, la organización y estructuración del proceso educativo por etapas, niveles y ciclos (artículo 2, BOE, número 238, página 28930).

Otro paquete de medidas aparece en el Real Decreto 986/1991, ${ }^{41}$ de 14 de junio, por el que se establece de forma progresiva los servicios de orientación y programas específicos de función especializada. La regulación de estructuras y funciones de orientación educativa y psicopedagógica se promueven por la Orden de 9 de diciembre de $1992^{42}$.

Fuera de las etapas dirigidas a educación infantil y primaria, cabe destacar en este punto los Reales Decretos 1179/1992, de 2 de octubre; el RD. 676/1993, de 7 de mayo y la anterior Orden de 25 de febrero de $1988^{43}$, sobre planificación de la educación especial, con regulaciones específicas para el alumnado con NEE en los niveles de bachillerato y formación profesional respectivamente.

Posteriormente, el RD 696/199544, de 28 de abril, de ordenación de la educación de los alumnos NEE, determina para las necesidades de carácter temporal o permanente a través de una serie de disposiciones, estableciéndose en su capítulo III, sección $1^{a}$, artículos 13 y 14, aquellas distinciones referidas a la atención en educación infantil y educación primaria. En su sección $2^{a}$, la escolarización en centros específicos solo para aquellos discentes con adaptaciones significativas permanentes y en grado extremo en las diferentes áreas del currículo oficial (artículo 19, pág. 11).

Prosiguen aunque de forma escasa, iniciativas como la Ley Orgánica 9/1995, de 20 de noviembre, de la participación, la evaluación y el Gobierno de los centros docentes $^{45}$ (LOPEG), la cual establece en su disposición adicional segunda aquellos aspectos sobre la escolarización de ACNEE (BOE, número 278, pág. 278) dentro de una progresiva serie de Resoluciones y Órdenes impulsadas por la Ley 1/1990, de 3 de octubre, como la Resolución de 30 de abril de 1996, de la Dirección General de renovación pedagógica, en la que se dictan instrucciones sobre el funcionamiento de los equipos de orientación educativa y psicopedagógica, en tareas de apoyo del alumnado en el proceso educativo y en las propuestas dirigidas a ellos, con las medidas y adaptaciones necesarias para aquellos alumnos que requieran de ella y específicamente si lo precisa el alumnado ACNEE.

Autores como (Barros \& Bosa, 2001; Blasco, 2006; Martín \& Margalef, 2000) definen como principio de mejora de la respuesta educativa la derogada Orden ${ }^{46}$ de 14 de febrero de 1996, por la que se regula el procedimiento para la realización de evaluación psicopedagógica y dictamen de escolarización. Además de establecer los criterios para la escolarización y evaluación del alumnado con NEE que cursan las enseñanzas de régimen general establecidas en la Ley 1/1990, de 3 de octubre, de Ordenación General del sistema educativo, destacando de ella aquellas que en su Capítulo II, sobre la escolarización del alumnado con NEE, que amplía la Ley

41. BOE, número 151, de 25 de junio de 2003. Referencia: BOE-A-1991-16269. Sitio web: https://www.boe.es/buscar/pdf/1991/BOE-A-1991-16269-consolidado.pdf

42. BOE, número 303, de 18 de diciembre de 1992. Referencia: BOE-A-1992-27998. Sitio web: https://www.boe.es/buscar/doc.php?id=BOE-A-1992-27998

43. BOE, de miércoles 22 de junio de 1988. Sitio web: https://www.boe.es/boe/dias/1988/06/22/pdfs/A19584-19586.pdf

44. BOE, número 131, de 2 de junio de 1995. Referencia: BOE-A-1995-13290. Sitio web: https://www.boe.es/buscar/act.php?id=BOE-A-1995-13290

45. BOE. Número 278, de 21 de noviembre de 1995. Sitio web: https://www.boe.es/boe/dias/1995/11/21/pdfs/A33651-33665.pdf

46. BOE, número 47, de 23 de febrero de 1996. Referencia: BOE-A-1996-4126. 
Orgánica 1/1990, en su punto 37.3 y prevé una escolarización en unidades y/o centros especializados "solo cuando las demandas del alumnado no puedan ser atendidas en un centro ordinario..." (BOE, número 45, de 23 de febrero de 1996, pág. 6918).

Otras de las normativas que se han de mencionar son la Orden de 22 de marzo de 1999 y la Ley Orgánica 5/200247, de 19 de junio, sobre cuestiones y gestiones en las cualificaciones de la formación profesional, texto consolidado posteriormente el 20 de junio de 2012 y que asegura en la disposición adicional sexta, punto 1, la formación del alumnado con necesidades específicas de apoyo educativo (ACNEAEE). Ese mismo mes, se firma el derogado también, Real Decreto 299/1996, de 28 de febrero de ${ }^{48}$ ordenación de las acciones dirigidas a la compensación de desigualdades en educación, siendo conscientes de las repercusiones negativas que las desigualdades educativas tienen sobre los aspectos sociales y que no ser tratadas en igualdad de oportunidades pueden convertirse en desigualdades a nivel global.

La Ley Orgánica 10/2002, de 23 de diciembre, de Calidad de la Educación (LOCE) ${ }^{49}$ contribuye y da un paso más hacia una respuesta educativa y social de calidad, y que responde no solo a concepciones de igualdad, sino de equidad. Nociones que se recogen junto a otros principios de calidad del sistema educativo, haciendo mención especial a la transmisión de valores, el principio compensador de las diferencias, el principio de participación, la responsabilidad en el proceso y la flexibilidad necesaria para cubrir las demandas de los discentes dentro de una adaptación instruccional (Miñambres y Jové, 2000, pág. 539). Ley que reconoce de nuevo, la importancia de las etapas educativas tempranas no solo en logros curriculares sino lo que es más importante, como competencias para "la vida" (Bofarull y Camps, 2019, pág. 34).

Una nueva etapa educativa da comienzo con la Ley $51 / 2003^{50}$, de 2 de diciembre, de igualdad de oportunidades, no discriminación y accesibilidad universal de las personas con discapacidad, de la Jefatura del Estado (LIONDAU). Disposición hoy en día derogada y que establecía claros impulsos hacía la participación y la accesibilidad universal (Capítulo I, BOE 289, página 43187), dejando atrás el modelo rehabilitador de políticas anteriores y advirtiendo un nuevo modelo social (Asís \& Palacios, 2007). Se destaca la transversalidad de dicha ley principalmente en su disposición final décima, "(...) la entrada en vigor de esta ley, desarrollará el currículo formativo en diseño para todos, en todos los programas educativos..."(BOE, número 289, pág. 18) con la definición clara del concepto de "persona con discapacidad" (BOE, 184, página 4) y de medidas contra la discriminación de las personas con discapacidad, exigiendo una accesibilidad total basada en "(...) los principios de accesibilidad universal del diseño para todos" (BOE número 289, artículo 7, punto b, pág. 8) especificando también en su artículo 10, el acceso a dichos bienes y servicios.

Ese mismo año, se dispone el Real Decreto 1537/2003, de 5 de diciembre, por el que se establecen los requisitos mínimos de los centros que imparten enseñanzas escolares en régimen general, decretando en la disposición adicional segunda, aquellas referencias propias para la educación especial.

47. BOE, número 127, de 20 de junio, de las cualificaciones de la formación Profesional. Referencia: BOE-A-2002-12018. Sitio Web: https://www.boe.es/ buscar/pdf/2002/BOE-A-2002-12018-consolidado.pdf

48. BOE, número 62, de 12 de marzo de 1996. Referencia: BOE-A-1996-5696. Sitio web: https://www.boe.es/buscar/doc.php?id=BOE-A-1996-5696

49. BOE, número 307, de 24 de diciembre de 2002. Sitio Web: http://www.madrid.org/dat norte/WEBDATMARCOS/sie/normativa loce/ley de calidad.pdf 50. BOE, número 289, de 3 de diciembre de 2003. Referencia: BOE-A-2003-22066. Sitio web: https://www.boe.es/buscar/act.php?id=BOE-A-2003-22066 
Influenciada por normativas internaciones y siguiendo las concreciones realizadas en Nueva York en diciembre del año 2006, sobre los derechos de las personas con discapacidad, emerge la universalización de los derechos de las personas con discapacidad (Álvarez, 2016) y que España ratifica en el BOE número 96, de lunes 21 de abril de 2008 (pág.20648-20659) destacando entre sus 50 artículos aquel expreso dedicado a la previsión de un sistema inclusivo para todas las enseñanzas, el derecho a no ser excluido del sistema educativo general por presentar una discapacidad (artículo 24, BOE ${ }^{51}$ número 96, pág. 20654) así como el derecho en ese mismo punto (apartado, c) de la realización de "ajustes razonables en función de las necesidades individuales" (pág. 20654). Definiendo a los ajustes razonables como "modificaciones y adaptaciones necesarias y adecuadas que no impongan una carga desproporcionada o indebida, cuando se requieran en un caso particular" (ONU, 2006, pág. 5; citado por Lombana \& Báez, 2018). Adaptaciones o ajustes como garantía de igualdad y de derecho para el alumnado con discapacidad (Guzmán \& Nieto, 2020).

Otras cuestiones que se contemplan son también aquellas medidas necesarias para el aprendizaje de aquellas experiencias formativas para la vida y para el desarrollo social (artículo 12, punto 3, BOE número 96, pág. 20654) como medidas de protección para más de medio centenar de millones de individuos con discapacidad dentro de la Unión Europea y 650 millones a nivel mundial (Cabra de Luna, Bariffi \& Palacios, 2009, pág. 142) de los cuales 150 millones corresponde a la población infantil (Castro\& Pelayo, 2008). Texto que de nuevo contempla la accesibilidad en su preámbulo reconociendo la importancia de la accesibilidad al entorno físico, social, económico y cultural, además ser beneficioso para la salud y la relaciones a través de la información y la comunicación (BOE número 96, pág. 20649). Otro de los artículos que es preciso reseñar es el artículo 9, dedicado a la accesibilidad y en el que determina medidas para asegurar el derecho a su participación en condiciones de igualdad, dentro de un compromiso expreso por los Estados miembros y dentro de un recorrido que exige una vez más, de una garantía pública que trabaje para alcanzar la igualdad de oportunidades en el alumnado (Palomares, 2004, pág.45).

Y en este sentido, la Ley Orgánica 2/2006, de 3 de mayo, de Educación (LOE) sitúa a la atención a la diversidad como una de sus mayores pretensiones. Favoreciendo la atención a los alumnos ACNEAE. Denominación que es empleada por primera vez en las leyes educativas de nuestro país para definir a aquellos alumnos con necesidades diferentes al resto. Con esta ley se diversifica la labor educativa y se dota al sistema de equidad, a través de una atención a la diversidad que cubre de mayor garantía al proceso educativo (Timón, M. \& Hormigo, F.) mostrando esta cualidad también en el principio de accesibilidad y su cumplimiento por parte de los centros docentes (art.10)

Ley, que en su preámbulo aporta una nueva esencia a la educación, la inclusión:

La adecuada respuesta educativa a todos los alumnos se concibe a partir del principio de inclusión, entendiendo que únicamente de ese modo se garantiza el desarrollo de todos, se favorece la equidad y se contribuye a una mayor cohesión social. La atención a la diversidad es una necesidad que abarca a todas las etapas educativas y a todos los alumnos. (BOE, número 106, de 4 de mayo de 2006, pág. 12-13). 
Haciendo una clara distinción en la clasificación (art. 71) del ACNEAE: alumnos con NEE, alumnos con dificultades específicas del aprendizaje (DEA), alumnos con altas capacidades, alumnos por su incorporación tardía al sistema educativo, y alumnos con condiciones personales o de historia escolar; y en los artículos 73-75 de forma expresa para el alumnado con NEE, destacando así, sus principios fundamentales basados en objetivos y directrices comunes, calidad educativa y el esfuerzo compartido (Timón \& Hormigo, 2010).

Siete meses más tarde, se aprueba el Real Decreto 1630/2006 52, de 29 de diciembre, por el que se establecen las enseñanzas del segundo ciclo de Educación Infantil, reglamento que expresa la intencionalidad de una atención a la diversidad dirigida a dicha etapa (Ortiz y Carrión, 2020). Se menciona de igual modo, un Real Decreto específico para Educación Primaria, el RD 1513/2006, de 7 de diciembre, quedando redactado en su artículo 13 aquellas medidas dirigidas a la atención a la diversidad del alumnado y desechado la diversidad bajo el prisma de la categorización (Aguado, 2013) evidenciando la importancia y la personalización de ésta en el proceso educativo.

Mencionar levemente normativas por sus impulsos transformadores como la Ley 7/2007, de 12 de abril, el Real Decreto 366/2007, de 16 de marzo y el RD 505/2007, de 20 de abril, con las condiciones básicas de accesibilidad y no discriminación, el Real Decreto 1494/2007, la Ley 56/2007 de 28 de diciembre y el Real Decreto 1544/2007, textos no vinculados directamente a la educación, pero que son citados por su atención y protección a través de concreciones sociales para las personas con discapacidad y por el establecimiento de aquellas condiciones de acceso, utilización de espacios y persistencia en el desarrollo y participación. En segundo lugar, la Ley 27/2007, de 23 de octubre, por la que se reconocen las lenguas de signos españolas, que regulan los medios de apoyo a la comunicación oral de las personas sordas, con discapacidad auditiva y sordociegas y en tercer lugar, la Ley 49/2007, de 26 de diciembre, de infracciones y sanciones en materia de igualdad de oportunidades, no discriminación y accesibilidad universal de las personas con discapacidad, con la finalidad de velar por su cumplimiento.

Se prosigue con aquellos datos destacados y llevados a cabo ese mismo año, donde España ratifica de la Convención sobre los Derechos de las Personas con Discapacidad $^{53}$ de 2006 y el Tratado de Lisboa ${ }^{54}$, firmado en diciembre de 2007, y en vigor desde mayo de 2008. Dichas disposiciones se desarrollan en base a la Ley Orgánica de 30 de julio de 2008 y que dicta entre sus 54 artículos de manera explícita, derecho a la Integración (artículo 26), así como el beneficio de aquellas determinaciones que legitimen principalmente su independencia, integración social y participación. En cuanto a la normativa que paralelamente se contempla sobre la normativa de accesibilidad se señala este mismo año, el Real Decreto 366/2007.

Dos años más tarde el Real Decreto $1635 / 2009$, de 30 de octubre ${ }^{55}$, regula la admisión de los alumnos en centros públicos y privados concertados, los requisitos

52. BOE, número 4, de 4 de enero de 2017. Referencia: BOE-A-2007-185. Sitio web: https://www.boe.es/buscar/doc. php?id=BOE-A-2007-185 53. BOE, número 97, de 22 de abril de 2008. Referencia: BOE-A-2008-6996. Sitio web: https://www.boe.es/buscar/doc.php?id=BOE-A-2008-6996 54. BOE, número 184, de 31 de julio de 2008. Referencia: BOE-A-2008-13033. Página web: https://www.boe.es/buscar/pdf/2008/B0E-A-2008-13033-consolidado.pdf 
que han de cumplir los centros que impartan el primer ciclo de la educación infantil y la atención al ACNEAE en el ámbito de gestión del Ministerio de Educación que de acuerdo con la Ley Orgánica 2/2006, determina entre sus solo ocho artículos, y dentro del capítulo IV, los principios generales del alumnado con necesidades específicas de apoyo educativo en general, cumpliendo en derecho y con el principio de igualdad (Artículo 5, punto 5, pág. 5). Real Decreto con destacado valor a la equidad, principalmente en la distribución de los alumnos.

En el año 2010 se aprueban las medidas oportunas a la Convención de la ONU. Estimaciones que son acordadas en el Consejo de Ministros de 30 de marzo y que responden al compromiso asumido por el estado español y que son ratificadas el 23 de diciembre de ese mismo año (BOE, número 184, página 4). Ley 26/201156, de 1 de agosto, de adaptación normativa a dicha Convención Internacional sobre los derechos de las personas con discapacidad, modifica la ley $51 / 2003$ y expone a través de sus 19 artículos la garantía de aquellas personas con discapacidad como titulares de pleno derecho. "Se pasa a considerar a las personas con discapacidad plenamente como sujetos titulares de derechos y no como meros objetos de tratamiento y protección social" (BOE número 184, de 31 de octubre modificado, página 3). Necesidad de amparo a los cerca de seiscientos millones de personas que a nivel mundial demandan dicho derecho, valor a ser estimado ya que representa a un $10 \%$ de la población mundial (BOE, número 184, pág. 87478). Así mismo y como medio para conseguir la igualdad social, se dicta el Real Decreto 173/2010, que, aunque dirigido a entornos no educativos sigue el recorrido necesario y convergente en atención a la diversidad y su acceso. Planos que hasta ahora se han complementado, que han caminado en paralelo, pero que sugieren una nueva perspectiva y régimen global e integral del concepto de igualdad.

Destacar un año más tarde el Real Decreto 1276/2011, de 16 de septiembre ${ }^{57}$, de adaptación normativa a la Convención Internacional sobre los derechos de las personas con discapacidad, con la creciente labor del Comité Español de representantes de personas con discapacidad (CERMI), designado por el Estado como defensor y revisor independiente al mismo en cuanto a la aplicación de la Convención sobre los Derechos de las Personas con Discapacidad (CDPD).

Fuera del ámbito educativo se cita el Real Decreto Legislativo $1 / 2013^{58}$, de 29 de noviembre, del Ministerio de Sanidad, Servicios Sociales e Igualdad, por su relación y relevancia al ámbito educativo. Legislación consolidada por la que se aprueba el texto refundido de la Ley General de derechos de las personas con discapacidad y de su inclusión social, donde se mencionan a lo largo de sus 105 artículos, un propuesta de garantía derivada de la misma, haciendo puntualizaciones concretas sobre las definiciones de términos como discapacidad, igualdad de oportunidades, discriminación directa, indirecta, y por asociación; acoso, medidas de acción positiva, vida independiente, normalización, inclusión social, accesibilidad y diseño universal, ajustes razonables, diálogo civil, y transversalidad. Amplitud de nociones y especificaciones que van teniendo cabida en el sistema educativo y social, puntualizando específicamente su capítulo IV, artículo 18, sobre el derecho a la educación inclusiva y dentro de un "sistema educativo inclusivo en todos los niveles educativos..."

56. BOE, número 184, de 2 de agosto de 2011. Referencia: BOE-A-2011-13241. Sitio web: https://www.boe.es/boe/dias/2011/08/02/pdfs/ BOE-A-2011-13241.pdf

57. BOE, número 224, de 17 de septiembre de 2011. Referencia: BOE-A-2011-14812. Sitio web: https://www.boe.es/buscar/doc.php?id=BOE-A-2011-14812 58. BOE. Número 289, de 3 de diciembre de 2013. Sitio web: https://www.boe.es/boe/dias/2013/12/03/pdfs/BOE-A-2013-12632.pdf 
(pág. 95645) insistiendo en medidas que se amplían y cubren al creciente número de alumnos con NEAE que ese mismo año es fijado por el INE en dos millones y medio de alumnos y alumnas con discapacidad reconocida (Nieto-Morales y Cordero, 2016, pág. 408). Este RD, también muestra la intención inclusiva en el contexto, es decir, prioriza la colaboración e inclusión en centros de enseñanza ordinarios, programas formativos y de sensibilización en atención a la diversidad para los profesionales (artículo 20, garantías adicionales.

La educación inclusiva formará parte del proceso de atención integral de las personas con discapacidad y será impartida mediante los apoyos y ajustes que se reconocen en el capítulo IV de este título y en la Ley Orgánica 2/2006, de 3 de mayo de Educación (Legislación consolidada, Ministerio de Sanidad, Servicios Sociales e Igualdad, BOE, número 289, de 3 de diciembre de 2013).

El criterio de inclusión se muestra como el "(...) indicador más obvio de la transición histórica..." (Viñao, 2006, pág. 48). Ley que deroga la Ley 13/ 1982, de integración social de las personas con discapacidad, la Ley 51/2003 de igualdad de oportunidades, no discriminación y accesibilidad universal de las personas con discapacidad y la Ley 49/ 2007.

\section{Periodo de Inclusión}

"Las políticas de las NEE son políticas de inclusión" (Martín \& Mauri, 2011) y estos avances inclusivos que vuelven a concretarse en la Ley Orgánica 8/2013, de 9 de diciembre, para la Mejora de la Calidad Educativa (LOMCE- Legislación consolidada) ${ }^{59}$ , especialmente en su sección cuarta para el alumnado con dificultades específicas del aprendizaje. En su artículo 79bis, y que establece las medidas para el alumnado con necesidades específicas, ampliando en el artículo 68, punto 57, la clasificación contemplada en el artículo 71 de la LOE sobre el ACNEAE y, manteniendo en vigor aquellas normativas contempladas en la misma dentro de un progreso y realidad social en continuo cambio que avanza hacia procesos educativos cada vez más democráticos y heterogéneos.

Acciones también fijadas en el Real Decreto 696/199560, de 28 de abril, de ordenación de la educación de los alumnos con necesidades educativas especiales, normativa que, aunque derogada, hace mención a programas específicos de integración (BOE, número 131, de 2 de junio de 1995, pág. 13290) como hecho de refuerzo y en virtud del compromiso transformador que viene otorgándose a la educación inclusiva (artículo 5) y calidad de la enseñanza (BOE, número 131, pág. 16181). R.D. que según no cumple con lo esperado, ni con la "(...) la voluntad de superar las disfunciones que venía manifestando el sistema educativo..." (pág. 16179) en el que sigue manteniéndose una dualidad de pensamientos entre a integración y la inclusión. Según Galofrey \& Lizán (2015) este R.D. muestra textos incompletos y terminología ambigua.

Un año más tarde se firma el Real Decreto 126/2014, de 28 de febrero ${ }^{61}$, por el que se establece el currículo básico de la Educación Primaria, dentro de su artículo 14, especifica aquellas intenciones sobre el alumnado con necesidades específicas de

59. BOE. Número 295, de 10 de diciembre de 2013. Referencia: BOE-A-2013-12886. Página web: https://www.boe.es/buscar/act.php?id=BOE-A-2013-12886 60. BOE, número 131, de 2 de junio de 1995. BOE-A-1995-13290. Sitio web: https://www.boe.es/buscar/doc.php?id=BOE-A-1995-13290

61. BOE, número 52, de 1 de marzo de 2014. Referencia: BOE-A-2014-2222. Sitio web: https://www.boe.es/buscar/pdf/2014/B0E-A-2014-2222-consoli$\underline{\text { dado.pdf }}$ 
apoyo educativo (ACNEAE) haciéndose cada vez más destacada la importancia dada a las medidas organizativas y las medidas de accesibilidad curricular en un proceso regido por los "(...) principios de normalización e inclusión y asegurará su no discriminación y la igualdad efectiva en el acceso y permanencia en el sistema educativo" ('BOE, número 52) medidas que según el informe anual del defensor del pueblo realizado ese mismo año, no se hacen efectivas. Texto que denuncia la segregación que continúa siendo evidente en los centros educativos españoles por la ausencia de recursos y adaptaciones específicas por parte de las administraciones educativas para el alumnado con NEAE escolarizado en centros ordinarios (Foschiani, 2017).

Al margen de numerosas normativas educativas autonómicas de gran importancia en esta última década, se ha de citar el Real Decreto 656/201962, de 18 de noviembre, en su anexo III, sobre actuaciones subvencionables para la participación del alumnado, determinando "Establecer, priorizar, desarrollar acciones y definir estrategias ..." para atención de las necesidades de los ACNEE (pág. 127304).

\section{Conclusiones}

Se constata que España, en paralelo a la trayectoria legislativa internacional una evolución y cambio en la normativa y política nacional tendente a facilitar respuestas educativas dirigidas al alumnado con necesidades específicas de apoyo educativo (ACNEAE), dentro de un recorrido hacia la inclusión, y determinado por un conjunto de dimensiones que según Campoy \& Palacios (2007) han respondido a la variante rehabilitadora y social bajo un recorrido de las leyes educativas dispuestas para el crecimiento social, humano y educativo, destacando en ellas la idea de adecuación al contexto concreto en la que se desarrollan, y la concreción de sus destinatarios, estableciéndose lo que López (2013) denomina una hegemonía dominante bajo un control en el que "la tecnocracia de la discapacidad ha apostado por el modelo biomédico y ha obviado, hasta bien entrado el siglo XX, el modelo social de la discapacidad" (Martínez y Planella, 2016, pág. 9) y que ha pasado del modelo de déficit al modelo inclusivo (Padilla, López \& Aguilar, 2018) dentro de un panorama educativo secuenciado y en el que se advierte de forma límpida y breve tres periodos: uno, como periodo de exclusión en la etapa coincidente con la Ley General de educación de 1970, dos, un periodo de integración en los años 80 promovido por la LISMI, y tres, un último periodo más inclusivo a partir de la ley LOE/LOMCE en el sistema educativo español.

Histórico de modelos que parten de la segregación del alumnado con necesidades específicas y evolucionan hacia la inclusión educativa; de las dificultades que presenta el individuo hasta las posibilidades que tiene, y de la homogeneidad educativa a la diversidad enriquecedora o heterogeneidad que presentan (Puigdellívol, 2007). Diversidad que se detalla en la actualidad por sus cualidades, advirtiéndose en su terminología la propiedad de multiplicidad y adición de la misma. "...La diversidad es algo inherente a cualquier ser vivo que habite en la tierra" (Colmenero, 2016, pág. 25). La diversidad, por lo tanto, es un hecho natural e innato, y la forma en la que es entendida se debe a un hecho social y cultural en continua transformación. Siendo necesario que los contextos formativos se conviertan en una "cultura escolar común" (Forteza \& Rosselló, 2002, pág. 337). “El nosotros se universaliza en torno a necesidades y funciones, que en los otros se particularizan" (Rosato y Angelino, 2009, pág.70) demostrando con ello el valor de la diversidad. 


\section{Bibliografía}

Aguado, T. (coord.). (2013) Diversidad e igualdad en educación. Madrid: Universidad Nacional de Educación a distancia.

Álvarez, T. (2016) Discapacidad y Universidad Española: protección del estudiante universitario en situación de discapacidad. Revista Derecho del Estado Universidad Externado de Colombia en el número 36 de julio-diciembre, 3-39. DOI: http://dx. doi.org/10.18601/01229893.n36.01

Arnaiz, P. (2005) Atención a la diversidad. Programación curricular. Costa Rica: Editorial Universidad Estatal a distancia (UNED).

Asís, R, \& Palacios, A. (2007) Derechos humanos y situaciones de dependencia. Madrid: Editorial DYKINSON, S.L.

Barros, V. \& Bossa, N.A. (coord.). (2001) Evaluación psicopedagógica de 7 a 11 años. Madrid: Ediciones Narcea, S.A.

Bisquerra, R. (1996) Orígenes y desarrollo de la orientación psicopedagógica. Madrid: Narcea, S.A. de Ediciones.

Blasco, P. (2006) Estrategias psicopedagógicas para la atención a la diversidad en educación secundaria. Valencia: Edicions Culturals Valencianes, S.A.

Bofarull, I. \& Camps J. (ed.). (2019) Habilidades para la vida. Familia y escuela. Madrid: Editorial Dykinson, S.L.

Botella, A.M. (coord.). (2018) Composición, investigación y docencia. Valencia: Universitat de Valencia.

Cabra de Luna, M.A., Bariffi F. \& Palacios, A. (coord.). (2009) Derechos humanos de las personas con discapacidad: la convención internacional de las Naciones Unidas. Madrid: Editorial Centro de Estudios Ramón Areces, S.A.

Campoy \& Palacios (coord.). (2007) Igualdad, no discriminación y discapacidad. Madrid: Editorial Dykinson, S.L. Instituto de derechos humanos Bartolomé de las Casas. Universidad Carlos III de Madrid.

Canales, J.M. \& Romero, A. (2018) Un estudio retrospectivo de la Ley de Instrucción pública de 1857: La Ley Moyano. Alicante: Publicaciones de la Universidad de Alacant.

Carreras, A. \& Tafunell, X. (coord.). (2005) Estadísticas históricas de España. Bilbao: Editorial Nerea, S.A.

Castro, C. \& Pelayo, J.D. (2008) Introducción a la protección internacional de los derechos del menor con discapacidad. En Cayo, L (d.) Los menores con discapacidad en España (página 163- 201) Madrid: Cermi. Grupo editorial CINCA.

Colmenero, M.J \& Pegalajar M.C. (2016) Atención educativa en centros específicos de educación especial. Madrid: Ediciones Paraninfo.

Delgado, V., Gomis, N., Mañas, C.R. \& Sánchez, V. (2013) Manual de Prácticas de Psicología evolutiva en primer ciclo de educación infantil. Alicante: Editorial Club Universitario.

Delgado, B. (coord.) (1994) Historia de la Educación en España y en América. Madrid: Ediciones SM.

Domenech, J. (2018) Teoría de la compensación social. Madrid: Visión Libros.

Escamilla, A., Lagares, A.R. \& García, J.A. (2006) La LOE: Perspectiva Pedagogía e Historia. Barcelona: Editorial GRAÓ, de IRIF, S.L.

Escobar, G. (2010) Personas con discapacidad. Madrid: Trama Editorial.

Fernández, J.M. (coord.). (2015) Atención a la diversidad en el aula de educación infantil. Madrid: Ediciones Paraninfo, S.A.

Fernández, M.D., \& Fernández, G. (coord) (2016) La escuela de ayer, hoy y mañana. Madrid: Editorial Dykinson, S.L.

Forteza, D. \& Rosselló, M.R. (coord.). (2002) Educación, diversidad y calidad de vida. Palma de Palma: Universitat de les Illes Balears. 
Foschiani, G. (2017) El rol del Comité de los derechos de las personas con discapacidad. Madrid: Editorial Centro de Estudios Ramón Areces, S.A.

Galofrey, R. \& Lizán, N. (2015) Una escuela para todos. Madrid: Ediciones de la Torre.

García, E. (2001) Evaluación de políticas y reformas educativas en España. Madrid: Instituto Nacional de Administración Pública.

Gómez, M.C. (2009) Aulas multisensoriales en educación especial. Vigo: Ideas propias editorial.

Grañera, M., Lameras, R.. Segalerva, A., Vázquex, E., Gordo, J.L. y Molinuervo, J. (1998) Catorce años de investigación sobre las desigualdades en educación en España. Madrid: Centro de Publicaciones- Secretaría General Técnica.

Gutiérrez, I. (1997) Introducción a la historia de la Logopedia. Madrid: Narcea, S.A. de Ediciones.

Guzmán, R. \& Nieto, A.B. (coord..). (2020) Políticas públicas en defensa de la inclusión, la diversidad y el género. Salamanca: Nueva Graficesa, S.L.

INEE (2016) Revisión de la OCDE de las políticas para mejorar la efectividad del uso de los recursos educativos. Informe país. Madrid.

Irimia, P. (2005) Superando la soledad: La educación de la persona con discapacidad intelectual. Madrid: Editorial Fundamentos.

Lombana, O.I.\& Báez. C.I. (comp.).(2018) Didácticas para la vida: Reflexiones desde una educación geográfica multidimensional e inclusiva. Bogotá: Universidad de Pedagogía Nacional, 2018.

López, S. (2013) Inclusión en la vida y la escuela: Pedagogía con sentido humano. Chile: Editorial Universidad de la Serena.

Martín, E., \& Mauri, T. (coord.). (2011) Orientación Educativa. Atención a la diversidad y educación Inclusiva. Barcelona: Editorial Graó, de IRIF, S.L.

Martín, M \& Margalef, L. (2000) La educación para la diversidad. Madrid: Universidad de Alcalá, Servicios de publicaciones.

Martínez, J.L. (ed.) (2005) Exclusión Social y Discapacidad. Comillas: Universidad Pontificia Comillas.

Martínez, O. \& Planella, J. (2006) Alterando la discapacidad: Manifiesto a favor de las personas. Barcelona: Editorial UOC.

Miñambres, A. \& Jové, G. (coord.). (2000) La atención a las necesidades educativas especiales de la educación infantil a la universidad. Lleida: Ediciones de la Universitat de Lleida.

Mora, J. \& Aguilera, A. (coord.). (2000) Dificultades en el aprendizaje del lenguaje, de las matemáticas y en la socialización. Sevilla: Editorial KRONOS.

Navaridas, F. (coord.). (2013) Procesos y contextos educativos: nuevas perspectivas para la práctica docente. Logroño: Genueve Ediciones.

Nieto-Morales, C. \& Cordero, N. (2016) La intervención social con menores. Madrid: Editorial Dykinson, S.L.

Ortiz, L. \& Carrión J.J. (2020) Reflexionando sobre la educación inclusiva: Una apuesta de futuro. Almería: Editorial Universidad de Almería.

Padilla, D., López, R. \& Aguilar, J.M. (eds.) (2018) Psicología, salud y educación. Almería: Editorial Universidad de Almería.

Palomares, A. (2004) Profesorado y educación para la diversidad en el siglo XXI. Cuenca: Ediciones de la Universidad de Castilla-La Mancha.

Puigdellívol, I. (2007) Educación especial en la escuela integrada. Barcelona: Editorial Graó, S.L.

Ríos, M. (2005) Manual de Educación Física adaptada al alumnado con discapacidad. Barcelona: Editorial Paidotribo.

Rodríguez, G. (coord). (2003) Las entidades voluntarias de acción social en España. Madrid: Fundación Foessa. 
Rosato, A. \& Angelino, M.A. (coord.). (2009) Discapacidad e ideología de la normalidad. Buenos Aires: Noveduc Libros.

Sánchez, A. (1997) Intervención psicopedagógica en educación especial. Barcelona: Edicions de la Universidat de Barcelona.

Sánchez, E. (1994) Introducción a la educación especial. Madrid: Editorial Complutense.

Stainback, S, \& Stainback, W. (2007) Aulas Inclusivas. Un nuevo modo de enfocar y vivir el currículo. Madrid. Narcea, S.A. Ediciones.

Timón, L.M. \& Hormigo, F. (coord.). (2010) Atención a la diversidad en el marco escolar: propuestas de integración para alumnos con necesidades específicas de apoyo educativo. Sevilla: Wanceulen Editorial Deportiva S.L.

Viñao, A. (2006) Sistemas educativos, culturas escolares y reformas. Madrid: Ediciones Morata, S.L.

\section{Anexo Legislación}

Constitución Española. BOE, número 311, de 29 de diciembre de 1978 (págs. 2931329424). Cortes Generales.

Decreto 1151/1975, de 23 de mayo, por el que se crea el Instituto Nacional de Educación Especial. Ministerio de Educación y Ciencia.

Decreto 1758/1960, de 7 de septiembre, por el que se modifica el título de la actual Escuela Nacional de Anormales. Ministerio de Educación Nacional.

Decreto 2925/ 1965, de 23 de septiembre por el que se regulan las actividades del Ministerio de Educación Decreto 2925/ 1965, de 23 de septiembre n Nacional en orden a la Educación Especial. Ministerio de Educación Nacional.

Decreto 334/1985 de 6 de marzo, de Ordenación de la Educación Especial. Ministerio de Educación y Ciencia.

Decreto 405/1984, de 22 de febrero, por el que se reestructura la composición de los órganos del Real Patronato de Educación y Atención a Deficientes. Presidencia del Gobierno.

Ley 1/1990, de 3 de octubre, de Ordenación General del Sistema Educativo. Jefatura del Estado.

Ley 13/1982, de 7 de abril, de Integración Social de los Minusválidos. Jefatura del Estado.

Ley 26/2011, de 1 de agosto, de adaptación a la normativa internacional sobre los Derechos de las personas con discapacidad. Jefatura del Estado

Ley 27/2007, de 23 de octubre, por la que se reconocen las lenguas de signos españolas y se regulan los medios de apoyo a la comunicación oral de las personas sordas, con discapacidad auditiva y sordociegas. Jefatura del Estado.

Ley 49/2007, de 26 de diciembre, por la que se establece el régimen de infracciones y sanciones en materia de igualdad de oportunidades, no discriminación y accesibilidad universal de las personas con discapacidad. Jefatura del Estado.

Ley $51 / 2003$, de 2 de diciembre, de igualdad de oportunidades, no discriminación y accesibilidad universal de las personas con discapacidad. Jefatura del Estado.

Ley 7/2007, de 12 de abril, del Estatuto Básico del Empleo Público. Jefatura del Estado.

Ley Orgánica 1/1990, de 3 de octubre, de Ordenación General del Sistema Educativo. Jefatura del Estado.

Ley Orgánica 10/2002, de 23 de diciembre, de Calidad de la Educación. Jefatura del Estado.

Ley Orgánica 2/2006, de 3 de mayo, de Educación. Jefatura del Estado.

Ley Orgánica 5/1980, de 19 de junio, por la que se regula el Estatuto de Centros Escolares.

Ley Orgánica 5/2002, de 19 de junio, de las cualificaciones y de la Formación Profesional. Jefatura del Estado. 
Ley Orgánica 8/2013, de 9 de diciembre, para la Mejora de la Calidad Educativa. Jefatura del Estado.

Ley Orgánica 9/1995, de 20 de noviembre, de la participación, la evaluación y el Gobierno de los centros docentes. Jefatura del Estado.

LODE 8/1985, de 3 de julio, reguladora del Derecho a la Educación. Jefatura del Estado.

Orden de 14 de febrero de 1996, por la que se regula el procedimiento para la realización de evaluación psicopedagógica y el dictamen de escolarización y se establecen los criterios para la escolarización de los alumnos con necesidades educativas especiales. Ministerio de Educación y Ciencia.

Orden de 14 de mayo de 1986 y por la que se revisa y corrige la de 30 de enero que, en cumplimiento de la disposición final primera del Real Decreto 334/1985, de 6 de marzo, de ordenación de la educación especial, establece las proporciones de personal/alumnos en esta modalidad educativa.

Orden de 15 de enero de 1990, sobre la planificación de la Educación especial y ampliación del Programa de integración para el curso 1991-1992. Ministerio de Educación y Ciencia.

Orden de 22 de marzo de 1999 por la que se regulan los programas de formación para la transición a la vida adulta destinados a los alumnos con necesidades educativas especiales. Ministerio de Educación y Cultura.

Orden de 24 de julio de 1962, por la que se dictan normas para solicitar la expedición del título de Profesores especializados en Pedagogía Terapéutica. Ministerio de Educación Nacional.

Orden de 25 de febrero de 1988, sobre planificación de la educación especial y ampliación del Programa de Integración en el curso 1988/89. Ministerio de Educación y Ciencia.

Orden de 25 de junio de 1980, por la que se desarrolla la organización y funciones del Patronato de Educación y Atención a Deficientes. Presidencia del Gobierno.

Orden de 30 de enero de 1986 por la que, en cumplimiento de la disposición final primera del Real Decreto 334/1985, de 6 de marzo, de ordenación de la educación especial, se establecen las proporciones de personal/alumnos en esta modalidad educativa. Ministerio de Educación y Ciencia.

Orden de 9 de septiembre de 1982, por la que se regula la composición y funciones de los equipos multiprofesionales dependientes del Instituto Nacional de Educación Especial. Ministerio de Educación y Ciencia.

Orden Ministerial de 20 de marzo de 1985, sobre la planificación de la educación especial y experimentación de la integración en el curso 1985-1986. Ministerio de Educación y Ciencia.

Orden Ministerial de 9 de diciembre de 1972, sobre confirmación de nombramiento de maestros en escuelas de educación especial.

Orden Ministerial de 9 de junio de 1989, por la que se aprueba las instrucciones de organización y funcionamiento de centros escolares.

Real Decreto 1023/1976, de 9 de abril, por el que se crea el Real Patronato de Educación Especial y se modifican determinados artículos del Decreto 1151/1975, de 23 de mayo. Ministerio de Educación y Ciencia.

Real Decreto 126/2014, de 28 de febrero, por el que se establece el currículo básico de la Educación Primaria. Ministerio de Educación, Cultura y Deporte.

Real Decreto 1276/2011, de 16 de septiembre, de adaptación normativa a la Convención Internacional sobre los derechos de las personas con discapacidad. Ministerio de Presidencia.

Real Decreto 1475/ 1986, de 11 de julio, por el que se reestructura el Real Patronato de Prevención y de Atención a Personas con minusvalía. Presidencia del Gobierno. 
Real Decreto 1475/1986, de 11 de julio, por el que se reestructura el Real Patronato de prevención y de atención a personas con minusvalía. Presidencia del Gobierno.

Real Decreto 1513/2006, de 7 de diciembre, por el que se establecen las enseñanzas mínimas de Educación Primaria. Ministerio de Educación y Ciencia.

Real Decreto 1537/2003, de 5 de diciembre, por el que se establecen los requisitos mínimos de los centros que imparten enseñanzas escolares en régimen general. Ministerio de Educación, Cultura y Deporte.

Real Decreto 1630/2006, de 29 de diciembre, por el que se establecen las enseñanzas del segundo ciclo de Educación Infantil. Ministerio de Educación y Ciencia.

Real Decreto 1635/2009, de 30 de octubre, por el que se regula la admisión de los alumnos en centros públicos y privados concertados, los requisitos que han de cumplir los centros que impartan el primer ciclo de la educación infantil y la atención al alumnado con necesidad específica de apoyo educativo en el ámbito de gestión del Ministerio de Educación. Ministerio de Educación.

Real Decreto 173/2010, de 19 de febrero, por el que se modifica el Código Técnico de la Edificación, aprobado por el Real Decreto 314/2006, de 17 de marzo, en materia de accesibilidad y no discriminación de las personas con discapacidad. Ministerio de la vivienda.

Real Decreto 2176/1978, por el que se encomienda al Ministerio de Sanidad y Seguridad Social la realización y gestión del Plan de Prevención de la Subnormalidad. Ministerio de Sanidad y Seguridad Social.

Real Decreto 2276/1976, de 21 de septiembre, por el que se regula el Real Patronato de Educación y Atención a deficientes. Presidencia del Gobierno.

Real Decreto 2276/1978, de 21 de septiembre, por la que se regula el Real Patronato de Educación y Atención a Deficientes. Presidencia de Gobierno.

Real Decreto 2639/1982, de 15 de octubre, de ordenación de la Educación Especial. Ministerio de Educación y Ciencia.

Real Decreto 2639/1982, de 15 de octubre, de ordenación de la Educación Especial. Ministerio de Educación y Ciencia.

Real Decreto 2828/1978, de 1 de diciembre, normativa reguladora del Real Patronato de educación y atención a deficientes,

Real Decreto 2828/1978, de 1 de diciembre, por los que se regula el Real Patronato de Educación y Atención a Deficientes. Presidencia del Gobierno.

Real Decreto 299/1996, de 28 de febrero, de ordenación de las acciones dirigidas a la compensación de desigualdades en educación. Ministerio de Educación y Ciencia.

Real Decreto 334/1985, de 6 de marzo, de Ordenamiento de la Educación Especial

Real Decreto 405/1984, de 22 de febrero, por el que se reestructura la composición de los órganos del Real Patronato de educación y atención a deficientes,

Real Decreto 505/2007, de 20 de abril, por el que se aprueban las condiciones básicas de accesibilidad y no discriminación de las personas con discapacidad para el acceso y utilización de los espacios públicos urbanizados y edificaciones. Ministerio de la Presidencia.

Real Decreto 556/89, en cumplimiento con los requisitos mínimos sobre accesibilidad en instituciones públicas

Real Decreto 696/1995, de 28 de abril, de ordenación de la educación de los alumnos Necesidades Educativas Especiales. Ministerio de Educación y Ciencia.

Real Decreto 967/1986, de 11 de abril, por el que los institutos nacionales de reeducación de inválidos, sordos y de pedagogía terapéutica se transforman en centros específicos de educación especial de régimen ordinario. Ministerio de Educación y Ciencia.

Real Decreto 969/1986, de 11 de abril, por el que se crea el centro Nacional de recursos para la Educación Especial. Ministerio de Educación y Ciencia. 
Real Decreto 986/1991, de 14 de junio, por el que se aprueba el calendario de aplicación de la nueva ordenación del sistema educativo. establece de forma progresiva servicios de orientación. Ministerio de Educación y Ciencia.

Real Decreto legislativo 1/2013, de 29 de noviembre, por el que se aprueba el texto refundido de la Ley General de derechos de las personas con discapacidad y de su inclusión social. Ministerio de Sanidad, servicios Sociales e Igualdad.

Real Decreto Legislativo de 1/2013, de 29 de noviembre, por el que se aprueba el texto refundido de la Ley General de derechos de las personas con discapacidad y de su inclusión social. Ministerio de Sanidad, servicios Sociales e Igualdad.

Reales Decretos 1179/1992, de 2 de octubre, por el que se establece el currículo de Bachillerato. Ministerio de Educación y Ciencia.

Resolución de 30 de abril de 1996, de la Dirección General de renovación pedagógica, por la que se dictan instrucciones sobre el Plan de actividades de los departamentos de Orientación de los Institutos de Educación Secundaria. (B.O.M.E.C., 13 de mayo de 1996, número 20) 